\title{
Perception and production of English fricatives by Chinese learners of English: Error patterns and perception-production relationship*
}

\author{
Buyi Zhang $\cdot$ Jiaqi Zhang** $\cdot$ Sook-hyang Lee \\ Department of English Language and Literature, Wonkwang University, Iksan, Korea
}

\begin{abstract}
This study examined the perception and production of eight English fricatives /f/, /v/, / $\theta /, / \delta /, / \mathrm{s} /, / \mathrm{z} /, / \mathrm{J} /$, and $/ 3 /$ by thirty Chinese English majors and thirty Chinese middle school students through a fricative identification test, an intelligibility test, and a goodness rating test and focused on error patterns and the perception-production relationship. The results showed that substitution errors occurred frequently in the perception and production of English fricatives by both the English majors and the middle school students. Further, the error patterns were attributed to various influencing factors such as the negative transfer from Chinese consonant inventory, hypercorrection or overcompensation mistakes, deficiency of L2 teaching, and acoustic similarities. Significant overall correlations were found between the fricative perception and production by the two subject groups but were not manifested in all the eight fricatives, indicating that Chinese learners' perceptual competence of target fricatives was not necessarily tied to their productive excellence of those sounds in all cases. Furthermore, precedences of perception over production were incompletely manifested in the eight fricatives, which suggested that perception might not always be a necessary prerequisite for production. Additionally, subject group and vowel context differences were observed. The English majors performed better than the middle school students, both perceptually and productively, and the subjects' performances in perception and production varied when vowel contexts changed.
\end{abstract}

Keywords: English fricatives, L2 perception, L2 production, error patterns, perception-production relationship

\section{Introduction}

In second language acquisition, theories have been proposed to explain the influence of learners' L1 on their L2 acquisition. Contrastive analysis hypothesis (CAH) (Lado, 1957) proposed that L2 learners have difficulty in acquiring L2 sounds that are different from their L1s and tend to replace the L2 sounds with sounds in their native sound system. For instance, French learners of English showed much learning difficulties in acquiring English dental fricatives $/ \theta /$ and $/ \delta /$ (both two sounds are absent in French) and substitute /s/ and /z/ for them (Major, 2001). However, with the increasing of evidence, $\mathrm{CAH}$ was found failed to predict some cases

\footnotetext{
* This work is recreated and expanded based on the contents of the first author's PhD dissertation with new subject group, improved statistical model and more elaborate discussions.

** zjq496166366@gmail.com, Corresponding author

Received 1 February 2021; Revised 16 March 2021; Accepted 18 March 2021

(c) Copyright 2021 Korean Society of Speech Sciences. This is an Open-Access article distributed under the terms of the Creative Commons Attribution NonCommercial License (http://creativecommons.org/licenses/by-nc/4.0) which permits unrestricted non-commercial use, distribution, and reproduction in any medium, provided the original work is properly cited.
} 
of L2 segment learning. In contrast to $\mathrm{CAH}$, Speech Learning Model (SLM) (Flege, 1995), and Perceptual Assimilation Model (PAM) (Best, 1995) suggested that the new L2 categories are more likely to be established by L2 learners when they are different from learners' native language. Take the EFL learning by Japanese learners of English for example: Japanese learners of English performed better in the acquisition of English / $/ \mathrm{/}$ than English /1/ even though English /I/ has greater dissimilarity with Japanese /r/ than English /1/ does (Aoyama et al., 2004; Sheldon \& Strange, 1982).

The focus of the present study is English fricatives, which are the largest consonant set in English in terms of manner of articulation. As observed by Cheng (2006), for Chinese learners of English, acquisitional errors among English consonants happen most frequently in the acquisition of fricatives. Researches on child language acquisition (Chen, 2011; Moeller \& Pat, 2007) also demonstrated that fricatives are late-acquired segments and child learners acquire fricatives later than stops. Specifically, in the present study we examined the perception and production of English fricatives by Chinese EFL learners as well as perception-production relationship.

Though previous researches have conducted various investigations on Chinese EFL learners' fricative acquisition as well as the relationship between perception and production, they were not free of limitations.

First, regarding the previous researches on the fricative acquisition of Chinese EFL learners:

1. Many previous researches only focused on theoretical discussions, and were often based on the authors' personal teaching experiences as English teachers (e.g., Niu, 2017; Sui \& Li, 1998; $\mathrm{Wu}, 2008)$. Empirical researches were short in quantity, especially those regarding the identification of English fricatives by the Chinese learners. Therefore, the present study used an fricative identification test, an intelligibility test and a goodness rating test so as to empirically examine the perception and production of English fricatives by Chinese EFL learners.

2. Previous researches often investigated individual fricative or certain fricative pairs (e.g., Rau et al., 2009; Xiao, 2013; Zhang \& Xiao, 2012), but rarely conducted comprehensive analyses for all of the English fricatives. In the present study, all the eight English fricatives were taken into consideration.

3. The previous researches did not provide highly satisfactory interpretations and explanations on the observed error patterns in that many of them simply attributed those patterns to the negative transfer of Chinese. Therefore the present study attempted to propose some new interpretations on the experimental results obtained.

Second, with regard to the previous researches on perceptionproduction relationship:

1. The results of the existing researches were mixed, some of which were even in conflict. Therefore, the present study was conducted with the aim of shedding some new lights on this intricate issue.

2. Researches on the relationship between the perception and production of English fricatives by Chinese learners is quite rare so far.

\section{Previous Researches}

2.1. Comparison of fricative systems between English and Chinese

In the consonant inventory of English, fricatives are the largest set in terms of manner of articulation, which are $/ \mathrm{f} /, / \mathrm{v} /, / \theta /, / \mathrm{d} /, / \mathrm{s} /$, $/ \mathrm{z} /, / \mathrm{J} /, / \mathrm{z} /$, and $/ \mathrm{h} /$. Most fricative-focused researches excluded voiceless glottal fricative $/ \mathrm{h} /$ because it was considered as the voiceless counterpart of its adjacent vowel (Ladefoged, 2014; Pike, 1943). Therefore the present study also excludes $/ \mathrm{h} /$ and only considers the other eight English fricatives (Table 1).

Table 1. English fricative inventory

\begin{tabular}{c|c|c}
\hline Place of articulation & Voiceless & Voiced \\
\hline Labio-dental & $/ \mathrm{f} /$ & $/ \mathrm{v} /$ \\
\hline Dental (Interdental) & $/ \Theta /$ & $/ \mathrm{d} /$ \\
\hline Alveolar & $/ \mathrm{s} /$ & $/ \mathrm{z} /$ \\
\hline Palato-alveolar & $/ \mathrm{g} /$ & $\mathrm{z} /$ \\
\hline Glottal & $/ \mathrm{h} /$ &
\end{tabular}

Referring the transcription proposed by Lin \& Wang (1992), Lin (2007), Duanmu (2007), we propose a six-membered fricative system of Chinese. There are five voiceless fricatives, which are labio-dental /f/, alveolar /s/, retroflex /s/, palatal /6/ and velar /x/, whereas the only voiced one is the retroflex / $/$ l (Table 2).

Table 2. Chinese fricative inventory

\begin{tabular}{c|c|c}
\hline Place of articulation & Voiceless & Voiced \\
\hline Labio-dental & $/ \mathrm{f} /$ & \\
\hline Alveolar & $/ \mathrm{s} /$ & $/ \mathrm{z} /$ \\
\hline Retroflex & $/ \mathrm{s} /$ & \\
\hline Palatal & $/ \mathrm{d} /$ & \\
\hline Velar & $/ \mathrm{x} /$ & \\
\hline
\end{tabular}

Similar to /f/ in English, Chinese /f/ is also a voiceless labiodental fricative, which is produced by making the inner surface of the lower lip slightly contact with the edge of the upper teeth. Then the escaping air produces friction and the fricative sound is articulated (Lin, 2007).

Chinese /s/, similar to English /s/, is also a voiceless alveolar fricative. In the articulation of Chinese /s/, the speaker makes the tongue tip or tongue blade slightly contact with the alveolar ridge and makes the tongue rims closely contact with the upper side teeth. Then friction is produced by the escaping air and the fricative sound is articulated. Lin (2007) called Chinese /s/ a dental sound but also proposed that it does not have an exact constriction location and can variably been classified as alveolar or dental or both. In the present study we classify Chinese /s/ as alveolar sound by following Ladefoged \& Maddieson (1996) and Lee \& Zee (2003) who claimed that some speakers might make use of the front part of the alveolar ridge to produce this sound.

In articulating Chinese $/ \mathrm{s} /$, which is a voiceless retroflex fricative, the tongue tip needs to curl up. More generally, it can be said that it is palato-alveolar without being palatalized. Namely, besides the prototypical subapical articulation, the tongue contact can be apical (pointed) or laminal (flat). The English fricative sharing the most articulatory similarity with Chinese $/ \mathrm{s} /$ is the voiceless palatoalveolar / $/$ / But Chinese /s/ and English / $/$ slightly differ in that 
Chinese $/ \mathrm{s} /$ has a retroflex articulation whereas English / $/$ does not. Also, for $/ \mathrm{J} /$, a speaker might feel that the air stream flows through the tongue blade and sometimes even a portion of the front of the tongue, while for $/ \mathrm{s} /$, the air stream is more limited to the tongue tip/blade area (Lin, 2007).

Chinese $/ 6 /$ is a voiceless alveolo-palatal sibilant fricative. The articulation of this sound involves three key points. First, the tongue should be made contact with the mouth roof in the area behind the alveolar ridge. Second, the tongue blade should contact the roof of the mouth. Third, the tongue middle is bowed and raised towards the hard palate, which means that this sound is heavily palatalized (Lin, 2007). We also regard the palato-alveolar / $/$ as a similar sound to Chinese /6/ in that both of them are post-alveolar sounds. But the two sounds slightly differ because Chinese /6/ is characterized by a softer (alveolo-palatal) pronunciation than English is.

Chinese $/ \mathrm{x} /$ is a voiceless velar fricative, which is auditorily similar to English $/ \mathrm{h} /$ and corresponds to the letter $\mathrm{h}$ in Chinese pinyin. Therefore we regard it as a similar sound of the voiceless glottal fricative / $/$ in English. But since English $/ \mathrm{h} /$ is not considered in the present study, Chinese / $\mathrm{x} /$ will not be discussed either.

Chinese $/ z /$ is the voiced counterpart of the voiceless retroflex sibilant fricative $/ \mathrm{s} /$ (Duanmu, 2007). Some phoneticians or phonologists (e.g., Lee \& Zee, 2003; Lin \& Wang, 1992) denied the existence of this sound in Chinese fricative system but we follow Duanmu (2007) because the Chinese " $r$ ", to which / $\mathrm{z}$ / is assigned, is characterized by its friction in articulation and is therefore more like a fricative sound. To articulate this sound, the air flow is channeled along a groove in the tongue back up to the place of articulation, at which point it is focused against the sharp edge of the nearly clenched teeth, causing high-frequency turbulence. We regard the voiced palato-alveolar $/ 3 /$ in English as the most similar sound to Chinese $/ \mathrm{z} /$ in that the relation between $/ \mathrm{s} /$ and $/ \mathrm{z} /$ is similar to that between $/ \mathrm{J} /$ and $/ 3 / . / \mathrm{s} /$ and $/ \mathrm{J} /$ are similar and accordingly we regard $/ z /$ and $/ 3 /$ as similar sounds. But these two sounds are slightly different in that Chinese / $z$ / is characterized by a retroflex articulation.

\subsection{Previous studies on the acquisition of English fricatives} by Chinese learners of English

As large differences exist in fricative inventories between English and Chinese, it has been observed that various perceptual and productive error patterns existed in the fricative acquisition of Chinese EFL learners. As reported by previous researches, the most frequently observed errors that Chinese EFL learners encountered in their fricative acquisitions mainly fell on $/ \mathrm{v} /, / \theta /, / \mathrm{\delta} /, / \mathrm{z} /, / \mathrm{J} /$, and $/ 3 /$. $/ \mathrm{f} /$ and /s/ were relatively well acquired for Chinese EFL learners in that no serious perceptual or productive deficiency has been reported by previous researches.

\subsubsection{Confusion pattern for $/ \mathbf{v} /$}

The substitution of $/ \mathrm{w} /$ for $/ \mathrm{v} /$ was on the top list in the fricative acquisition by Chinese EFL learners. Cheng \& He (2008) found that the substitution error of $/ \mathrm{v} /-\mathrm{w} /$ happened even for advanced Chinese EFL learners. They analyzed the reason for such an error and claimed that it might be the absence of $/ \mathrm{v} /$ sound in Chinese that made Chinese learners replace the new L2 sounds with the similar sounds in their L1 Chinese or the L2 sounds they were familiar with.

Xiao (2013) and Zhang \& Xiao $(2011,2014)$ also observed that Chinese learners of English showed extreme difficulty in productively distinguishing / $/ \mathrm{l}$ and $/ \mathrm{w} /$ in the reading tests. Xiao (2013) claimed that the main reason for this substitution is the lack of voiced fricative as $/ v /$ in Chinese. Since no equivalent or semi-eviqualvent for $/ \mathrm{v} /$ exists in Chinese, subjects are unfamiliar with the accurate way of articulation. Consequently, they do not have a clear idea of how to pronounce $/ \mathrm{v} /$ and therefore replace it with $/ \mathrm{w} /$ to save effort.

Chen \& Bi's (2008) also reported that Chinese learners had difficulty in telling the differences between $/ \mathrm{v} /$ and $/ \mathrm{w} /$. And they attributed the problem to a mechanism of "least effort", which is likely to make L2 learners use the most similar sounds in their L1 or L2 to avoid the pronunciation difficulty in the production of new sounds they are not familiar with.

$\mathrm{Wu}$ (2008) compared the places of articulation between English and Chinese fricatives in a comparative study and reported that Chinese learners would replace English $/ \mathrm{v} /$ with Chinese semivowel/glide $/ \mathrm{w} /$ based on his own teaching experiences as a college English teacher. He claimed that negative transfer from L1 to L2 is the key cause of the errors in the English fricative production by Chinese learners. He suggested that the substitution errors should be attend to and the way of learning should be reconsidered.

\subsubsection{Confusion patterns for $/ \boldsymbol{\theta} /$ and $/ \boldsymbol{\delta} /$}

The acquisitional problems for dental fricatives $/ \theta /$ and $/ \delta /$ were also serious in the fricative acquisition by Chinese learners of English. Li (2012), Sui \& Li (1998), and Wu (2008) all reported Chinese learners of English tended to replace English fricatives $/ \theta$ / and $/ \delta /$ with $/ \mathrm{s} /$ and $/ \mathrm{ts} /$. They ascribed such error patterns to the fact that Chinese EFL learners fail to master the feature of tongue position in articulating these two dental sounds. Learners are not aware of using the tongue tip and rims to make a slight contact with the edge and inner surface of the upper incisors and a contact with the upper side teeth.

Rau et al. (2009) recruited 27 Chinese learners of English and investigated their production of English dental fricative $/ \theta /$. The Chinese learners were asked to evaluate the acceptability of several possible substitutes for the "th" sound. And they were required to participate in four production tasks. The results revealed that Chinese speakers rated [s] as the most acceptable substitute for "th".

Xiao (2013) found that Chinese learners had difficulties in producing English / $ठ /$ and ascribed the result to the negative transfer of Chinese. Many subjects misproduced "breathe" as "breeze" in the reading task, which indicated that they substituted $/ \mathrm{z} /$ for $/ \delta /$. Moreover, Cheng \& He (2008) also observed such an substitution pattern in their analyses of oral segmental errors of Chinese advanced English learners. They reported that Chinese learners were likely to replace $/ \delta /$ with $[\mathrm{z}]$ and the reason for Chinese learners' substitution of $[\mathrm{z}]$ for $/ \mathrm{\delta} /$ was that there is no equivalent sound to $/ \mathrm{d} /$ in Chinese. Additionally, the same confusion pattern was also observed by Zhang \& Xiao (2012).

Niu (2017) stated that due to the articulatory similarities that English and Chinese fricatives share, Chinese learners of English often make mistakes in the place of articulation of English fricatives and use similar phonemes from their L1 Chinese to replace the English fricatives. Similar as Wu (2008)'s comparative study, she also compared Chinese and English fricative inventories and classified the common mistakes of English majors in producing English fricative sounds based on her own teaching experience as an English teacher. She pointed out that Chinese English majors might replace English / $\theta /$ or /ठ/ with Chinese /s/ or /d/. 


\subsubsection{Confusion pattems for $/ \mathbf{z} /$}

/z/ was also a problematic one for Chinese EFL learners. According to Cheng \& He (2008)'s observation. Chinese learners substituted $/ \mathrm{s} /$ for $/ \mathrm{z} /$ as a result of the absence of $/ \mathrm{z} /$ in Chinese consonant system. Chinese learners might also replace /z/ with /ts/, which is an affricate sound in Chinese consonant system.

\subsubsection{Confusion pattems for $/ \mathrm{J} /$ and $/ 3 /$}

$/ \mathrm{J} /$ and $/ 3 /$ were also challenging for Chinese EFL learners. Xiao (2013) observed in the reading test that Chinese learners substituted $/ \mathrm{s} /$ for $/ \mathrm{J} /$, and /z/ for /3/ respectively. Wu (2008) and Niu (2017) also reported perceptual and productive confusions between $/ \mathrm{s} /$ and $/ \mathrm{J} /$, and between $/ 3 /$ and $/ z /$ based on their own teaching experiences. Moreover, Zhang \& Xiao (2014) also found serious bidirectional confusion between $/ \mathrm{J} /$ and $/ 3 /$. They claimed that the substitution of / $/$ for $/ 3 /$ was an instantiation of devoicing phenomenon while the substitution of $/ 3 /$ for $/ \mathrm{J} /$ was an unexpected one.

In summary, previous studies have shown that Chinese EFL learners had various difficulties in acquiring English fricatives, and the main reason is the lack of corresponding or similar sounds in Chinese and the negative transfer of L1.

\subsection{Previous studies on the correlation between perception and production}

The intrinsic relationship between perception and production has attracted much attention over the past decades. Previous researches concerning the perception-production relationship in second language acquisition have yielded conflicting results.

Many researches on second language acquisition proposed that perception may be a necessary prerequisite for production. L2 learners need sufficient authentic input before they can really produce the target sounds accurately (Major, 2001). For instance, Flege et al. (1997) found that L2 learners' perceptual sensitivity to the spectral and durational cues in English vowels /i, I, æ, e/ could explain a great proportion of variance in L2 learners' production. Likewise, Flege (1999) carried out an experiment to examine the perception and production of 10 English vowels by Italian EFL learners. Results revealed that Italian learners' vowel perception scores significantly correlated with their vowel production accuracy. Two years later, Joh \& Lee (2001) studied the perception and production of three English fricatives /s $\theta_{3} /$ before three vowels /i a u/ by Korean college students and they observed a precedence of Korean participants' perception over their production.

More recently, the research by Owolabi (2012) offered further support for the precedence of perception over production. He discussed the perceptual and productive difficulties of English dental fricatives $/ \theta /$ and $/ \delta /$ of Yoruba learners of English and proposed that Yoruba learners might have difficulties in producing these two fricatives, but they seemingly had little difficulties in perceiving them, as revealed by the mutual intelligibility. Zhang \& Lee (2018) investigated the perception and the acoustic features of four English voiceless fricatives /f/, / $\theta /, / \mathrm{s} /$, and $/ \mathrm{f} /$ by Chinese EFL learners and found that the intensity and noise duration of the four fricatives produced by Chinese EFL learners had an influence on their fricative perception, which also provided support for perception- production relationship.

However, some research reported that L2 learners may produce target L2 segments correctly without perceiving them accurately, of which the most often mentioned example is the acquisition of
English /1/-/r/ contrast by Japanese learners of English. Sheldon \& Strange (1982) reported that Japanese learners of English could produce $/ 1 /-/ \mathrm{r} /$ contrast accurately but they had very poor perception of it. The possible reason is that even though the large amount of articulatory training has made Japanese EFL learners capable of producing these two sounds accurately, they are unable to map the acoustic cues of these two sounds into separate phoneme. Bohn \& Flege (1990) observed that German learners of English showed better performance in producing the vowel pair $/ \mathfrak{m} /-/ \varepsilon /$ than perceiving it. Later, Tsukada et al. (2005) investigated the perception and production of English vowels by native Korean adult and child speakers of English, and found that the child speakers performed better in producing the target vowels than in perceiving them. Lee et al. (2011) examined the perception and production of the four English voiceless fricatives /f, $\theta, \mathrm{s}, \mathrm{g} /$ by 21 Korean advanced EFL learners and suggested that Korean learners' perceptual difficulty of the target fricatives was not necessarily related to their deficient production or vice versa.

\section{Method}

\subsection{Subjects}

The participants were recruited from altogether three populations. The first participant group was a native speaker group including 5 male and 5 female native speakers of English from the U.S., who were school teachers or exchange students in Tianjin Foreign Studies University and were able to speak General American without any speech disorders. The second participant group was the Chinese English major group with 15 male and 15 female English majors with no experience of living in an English-speaking country, who have been studying in Hebei Normal University for Nationalities in Chengde city, China, for three years. The 30 English majors all have been learning English as a foreign language for more than 12 years and have passed Test for English Majors Band 4 (an annual English proficiency test in speciality designed for English majors in China, hereafter, test for English majors [TEM] 4) with mean score of 67.8 (ranging from 63 to 70). TEM 4 is an English-major-oriented proficiency test of English, which comprehensively examines Chinese English majors' English vocabulary, grammar, abilities of listening, reading and writing. Previous researches (Jin \& Fan, 2011; Tian, 2015) suggested that TEM 4 was a reliable and valid English proficiency test and was designed at an appropriate difficulty level. Chen (2012) reported a significant correlation between testees' TEM4 scores and their English learning motivation and effort. Moreover, according to statistics, the passing rate of TEM 42019 in China was merely $52.96 \%$, which means that even for English majors, passing the TEM 4 was a challenge. The third participant group was the Chinese middle school student group, consisting of 15 male and 15 female middle school students in Chengde city, China, who also did not have any experience of living in an English-speaking country. All of these middle school students have passed the Middle School Entrance Examination with a mean score of 74.7 (ranging from 70 to 79). As a teenager-oriented English proficiency test, Middle School Entrance Examination is designed with simple questions of English vocabulary and grammar, as well as straightforward tests of listening, reading, and writing abilities.

Independent sample t-tests were conducted to examine whether significant differences existed in lengths of English learning (LEL) 
and age of learning (AOL) between English major group (mean LEL, 12.8 years; AOL, 9.1) and middle school student group (mean LEL, 4.1 years; mean AOL, 9.2). Results showed that English majors had significantly longer LEL than middle school students did $(p<.001)$ while the effect of AOL did not reach statistical significance $(p=.739>.05)$. This means that the English majors were more experienced English learners than the middle school students were and the two subject groups were not distinguished by AOL.

\subsection{Research materials}

As presented in Table 3, the stimuli materials were $/ \mathrm{CV} /$ structures with $\mathrm{V}$ being one of the eight English fricatives $/ \mathrm{f} /, / \mathrm{v} /, / \theta /, / \mathrm{d} / \mathrm{,} / \mathrm{s} /$, $/ \mathrm{z} /, / \mathrm{J} /$, and $/ \mathrm{z} /$ and $\mathrm{C}$ being one of the three cardinal vowels $/ \mathrm{i} /, / \mathrm{a} /$, and $/ \mathrm{u} /$. All of them were combinations of IPA symbols so as to eliminate word frequency effect and the carrier sentence was "Say to me."

Table 3. Stimuli materials for English fricatives

\begin{tabular}{|c|c|c|c|}
\hline & /i/ context & $/ \mathrm{a} /$ context & $/ \mathrm{u} /$ context \\
\hline$/ \mathrm{f} /$ & Say /fi:/ to me. & Say /fa:/ to me. & Say /fu:/ to me. \\
\hline$/ \mathrm{v} /$ & Say /vi:/ to me. & Say /va:/ to me. & Say /vu:/ to me. \\
\hline$/ \theta /$ & Say /Өi:/ to me. & Say $/ \theta a: /$ to me. & Say $/ \theta u: /$ to me. \\
\hline /ð/ & Say /ði:/ to me. & Say /ða:/ to me. & Say /ðu:/ to me. \\
\hline$/ \mathrm{s} /$ & Say /si:/ to me. & Say /sa:/ to me. & Say /su:/ to me. \\
\hline$|z|$ & Say /zi:/ to me. & Say /za:/ to me. & Say/zu:/ to me. \\
\hline$/ \mathrm{d} /$ & Say / /i:/ to me. & Say / $\mathrm{da}: /$ to me. & Say /Ju:/ to me. \\
\hline$/ 3 /$ & Say /zi:/ to me. & Say /za:/ to me. & Say/zu:/ to me. \\
\hline
\end{tabular}

\subsection{Experimental procedures}

In order to prepare the stimuli to be used in the experiments, all the 70 participants (10 native speakers, 30 Chinese English majors and 30 Chinese middle school students) were asked to read 24 randomized carrier sentences ( 8 fricatives in 3 vowel contexts) 3 times and recorded by a Zoom H1 recorder. After that three experiments were conducted. Experiment 1 was a perception test, which investigated Chinese learners' identification of English fricatives produced by native speakers of English. Experiment 2 was also a perception test, which examined native speakers' identification of English fricatives produced by the Chinese learners. Namely, Experiment 2 examined the intelligibility of English fricatives produced by the Chinese learners. Experiment 3 was a goodness rating test, where Chinese learners' productions of English fricatives were rated by the native speakers based on pronunciation goodness.

\subsubsection{Experiment 1: Identification test}

Productions by all the 10 native speakers were extracted and used as stimuli in the identification test (tokens: 10 native speakers $\times 8$ fricatives $\times 3$ vowel contexts $\times 3$ repetitions $=720$ ). Each of the 30 Chinese English majors and 30 Chinese middle school students listened to the 720 carrier sentences including the target fricatives produced by the native speakers in a random order on a laptop running an experiment script on Praat. The participants were required to identify the target fricatives in the carrier sentences. Eight options were presented on the screen, with each one labeled in IPA with one of the eight English fricatives, and listeners could use the mouse to click on one of the buttons to make their selection. To ensure that each response is effectively generated, a "Replay" button and a "Back to previous" button were also provided in the answer board. The participants were allowed to click on them when they thought it necessary. Each correct identification won 1 point. For each target word (/vi:/, /sa:/, /3u:/ etc.) perceived by each Chinese participant, the identification accuracy ranged from $0 / 30$ to $30 / 30$ (productions by 10 native speakers $\times 3$ repetitions $=30$ ). To get rid of the effect of fatigue, a break was inserted after every 20 tokens. The participants could stop at each of the breaks and take a break as long time as they needed.

\subsubsection{Experiment 2: Intelligibility test}

All the 10 native speakers were paid to listen to the carrier sentences including the target fricatives produced by the 30 Chinese English majors and 30 Chinese middle school students (tokens: 60 Chinese learners $\times 8$ fricatives $\times 3$ vowels $\times 3$ repetitions $=4,320$ ) and identify the target fricatives in the carrier sentences. Same as Experiment 1, the 4,320 tokens were played to each native speakers in a randomized order on a laptop running the same script on Praat and each correct identification also won 1 point. Given that the workload was heavy and the fatigue effect of the subjects might interfere with the accuracy of the experimental results, the whole experiment were separated into two times to finish and we also inserted a break after every 20 tokens.

Based on the fricative identification by the native speakers, we obtained the intelligibility score of each target word for the Chinese learners, ranging from $0 / 90$ to $90 / 90$ (productions by 30 Chinese English majors or 30 Chinese middle school students $\times 3$ repetitions). Furthermore, in case the native speakers did not think any one of the eight fricative options was the sound they just heard, they were required to click on the "Other" button and type in the IPA symbols of the sound they thought they really heard in an excel file provided to them. The native speakers were allowed to type in a question mark ("'?) when they could not decide which IPA symbol should be assigned to the target sound. The excel files were reexamined by the researchers later and all the question marks were assigned appropriate IPA symbols based on the judgement of the researchers. Within all the 4,320 tokens, it was found that "?" took up 325 of them (7.5\%) and were mostly used for the identification of $/ 3 /$ by the native speakers.

\subsubsection{Experiment 3: Goodness rating test}

2 English-speaking judges (1 male and 1 female with an MIB degree; inter-rater reliability: 0.89 ) from the U.S. were invited and paid to listen to and rate the production of English fricatives by 30 Chinese English majors and 30 Chinese middle school students (tokens: 60 learners $\times 8$ fricatives $\times 3$ vowel contexts $\times 3$ repetitions $=$ 4,320 ) in a 5-scaled rating (Table 4 ).

\subsection{Statistical analyses}

The identification accuracy, intelligibility score and goodness rating score obtained from the identification test (Experiment 1), intelligibility test (Experiment 2) and goodness rating test (Experiment 3) were calculated into percentage (\%). As for the relationship between perception and production, Pearson Bivariate Correlation Analyses were conducted crosswise between the results of the three tests in SPSS 22. Namely, Pearson Bivariate Correlation Analyses were conducted respectively for the results between identification test (Experiment 1) and intelligibility test (Experiment 2), and between identification test (Experiment 1) and goodness rating test (Experiment 3). 
Table 4. 5-scale rating used in the goodness rating test

\begin{tabular}{c|l}
\hline Rating & \multicolumn{1}{c}{ Explanation } \\
\hline 4 & $\begin{array}{l}\text { The pronunciation is perfect and completely native-like. } \\
\text { The native judge cannot detect any foreign accent. }\end{array}$ \\
\hline 3 & $\begin{array}{l}\text { The pronunciation is correct but the native judge can still } \\
\text { sense some slight foreign accents. }\end{array}$ \\
\hline 2 & $\begin{array}{l}\text { The pronunciation is correct but the native judge can } \\
\text { detect obvious foreign accents. }\end{array}$ \\
\hline 1 & $\begin{array}{l}\text { The pronunciation is wrong but the native judge can still } \\
\text { know what sound the speaker is trying to produce. }\end{array}$ \\
\hline 0 & $\begin{array}{l}\text { The pronunciation is totally wrong and it is not even } \\
\text { understandable. The native judge cannot even decide } \\
\text { what sound is actually produced. }\end{array}$ \\
\hline
\end{tabular}

\section{Results and Discussions}

\subsection{Fricative type and subject group differences}

\subsubsection{Identification test}

Figure 1 display the mean identification accuracy of the eight fricatives for both Chinese English majors and middle school students. The mean identification accuracies for the English majors were in the hierarchy: $/ \mathrm{J} /(96 \%)>/ \mathrm{f} /(88.9 \%)>/ \mathrm{v} /(87.2 \%)>/ 3 /$ $(84.1 \%)>/ \mathrm{s} /(80.7 \%)>/ \mathrm{z} /(75 \%)>/ \theta /(39.8 \%)>/ \delta /(31.6 \%)$, while the corresponding results for the middle school students were: $/ \mathrm{J} /$ $(92.3 \%)>/ f / \quad(80.3 \%)>/ 3 / \quad(75.5 \%)>/ \mathrm{s} / \quad(72.3 \%)>/ \mathrm{v} / \quad(68.7 \%)>/ \mathrm{z} /$ $(64.7 \%)>/ \theta /(26.3 \%)>/ ठ /(20.5 \%)$. Both two subject groups obtained the highest accuracy in identifying $/ \mathrm{J} /$ but showed the most difficulty in identifying the two dental fricatives $/ \theta /$ and $/ \delta /$.

Three-way ANOVA with fricative, subject group and vowel context as factors was performed on Chinese subjects' identification accuracy. The results showed that there were main effects of fricative $[F(7,1392)=599.91, p<.001]$, subject group $[F(1,1392)=210.088$, $p<.001]$ and vowel context $[F(2,1392)=6.29, p=.002<.01]$ on Chinese subjects' identification accuracy.

A subject group $\times$ fricative interaction $[F(7,1392)=4.601, p<.001]$ was found and corresponding post hoc tests showed that Chinese English majors had significantly higher identification accuracy than Chinese middle school students in perceiving all the other seven fricatives except for $/ \mathrm{J} /$, which means that the longer exposure of L2 facilitated their identifications of most fricatives.

A fricative $\times$ vowel interaction $[F(14,1392)=18.26, p<.001]$ was found and corresponding post hoc tests showed that the differences in Chinese subjects' identification accuracy between the three vowel context were only carried by $/ \mathrm{f} /, / \Theta /, / \delta /$, and /z/. /f/, and /ð/ were the best identified in $/ \alpha /$ context while $/ \theta /$ and $/ z /$ were the best identified in $/ \mathrm{u} /$ and $/ \mathrm{i} /$ contexts respectively.

A non-significant subject group $\times$ vowel interaction $[F(2,1392)=$ .797, $p=.451>.05]$ indicated that the accuracy differences between the three vowel context were in parallel between the English majors and the middle school students.

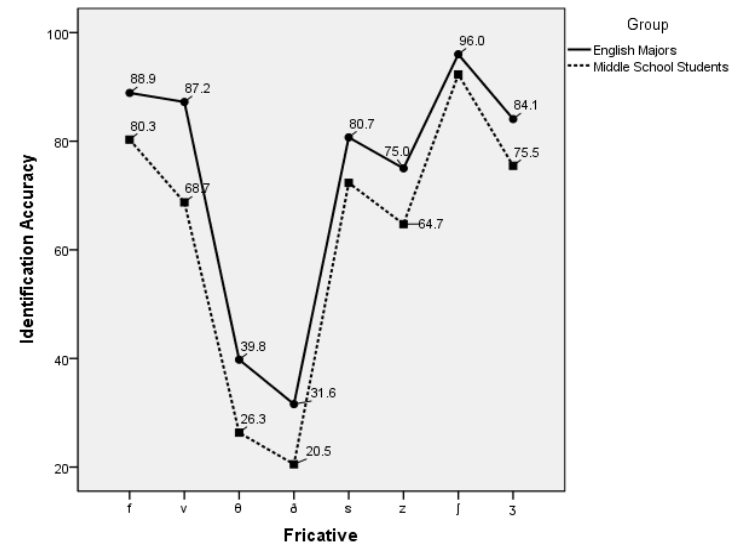

Figure 1. Mean identification accuracy of each English fricative for Chinese subject

\subsubsection{Intelligibility test}

Figure 2 demonstrated the mean intelligibility score of the eight fricatives for Chinese English majors and middle school students. The order of the mean intelligibility score of the English majors were: / $/(95.2 \%)>/ f /(94.7 \%)>/ \mathrm{s} /(90.6 \%)>/ \mathrm{z} /(82.2 \%)>/ \mathrm{v} /(70.7 \%)>$ $/ \theta /(51.1 \%)>/ \delta /(48.6 \%)>/ 3 /(41.1 \%)$, whereas those of the middle school students were: $/ \mathrm{f} /(92.2 \%)>/ \mathrm{f} /(89.2 \%)>/ \mathrm{s} /(87.4 \%)>/ \mathrm{z} /$ $(74.1 \%)>/ v /(46.6 \%)>/ 3 /(24.3 \%)>/ \theta /(18.5 \%)>/ 0 /(15.4 \%)$. Similar to the results of identification test, both the English majors and the middle school students produced $/ \mathrm{J} /$ with the highest intelligibility. However, the least intelligible fricative produced by the English majors was $/ 3 /$ while that by the middle school students was $/ \delta /$, followed by $/ \theta /$.

Three-way ANOVA with fricative, subject group and vowel context as factors was performed on Chinese subjects' intelligibility score. The results showed that there were main effects of fricative $[F(7,1392)=1110.241, p<.001]$, subject group $[F(1,1392)=723.968$, $p<.001]$ and vowel context $[F(2,1392)=22.715, p<.01]$ on Chinese subjects' intelligibility score.

A subject group $\times$ fricative interaction $[F(7,1392)=59.115, p<.001]$ was found and corresponding post hoc tests showed that English majors had significantly higher intelligibility than middle school students in producing all the other six fricatives except for $/ \mathrm{s} /$ and $/ \mathrm{S} /$, indicating that a longer exposure of L2 was related to a more intelligible fricative production in most cases.

A fricative $\times$ vowel interaction $[F(14,1392)=3.819, p<.001]$ was found and corresponding post hoc tests showed that the differences in Chinese subjects' intelligibility score between the three vowel context were only carried by $/ \mathrm{f} /, / \theta /, / \mathrm{d} /$, and $/ \mathrm{J} /$ and all these four fricatives were the most intelligible in the $/ \mathrm{u} /$ context.

A non-significant subject group $\times$ vowel interaction $[F(2,1392)=$ $.185, p=.831>.05]$ indicated that the intelligibility differences between the three vowel contexts were not significant between English majors and middle school students. 


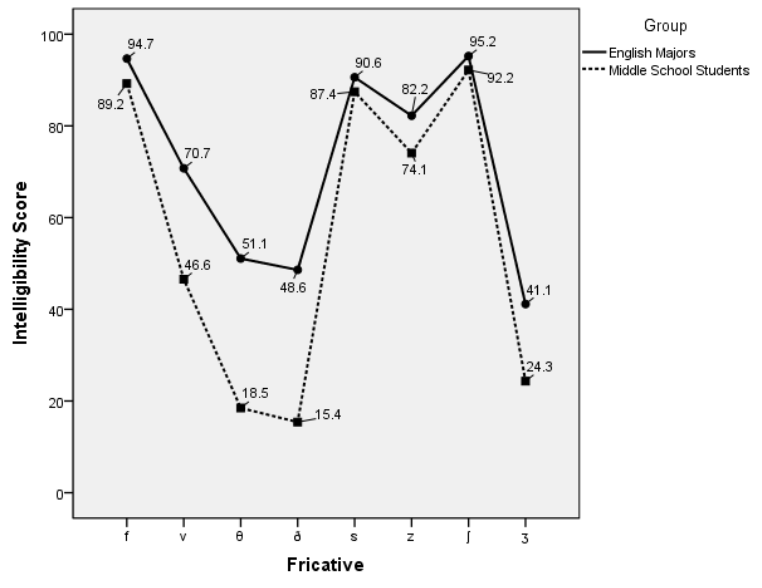

Figure 2. Mean intelligibility score of each English fricative for Chinese subjects

\subsubsection{Goodness rating test}

Figure 3 shows the average goodness rating score of the eight fricatives for the two groups. The average goodness rating scores of the English majors were in the order: $/ \mathrm{J} /(98.42 \%)>/ \mathrm{f} /(98.38 \%)>/ \mathrm{s} /$ $(96.3 \%)>/ \mathrm{v} /(92.1 \%)>/ \mathrm{z} /(91.4 \%)>/ \theta /(79 \%)>/ \circlearrowright /(78.9 \%)>/ 3 /(53 \%)$, while those of the middle school students were in the hierarchy: /J/ $(94.6 \%)>/ \mathrm{f} /(92.8 \%)>/ \mathrm{s} /(91.3 \%)>/ \mathrm{z} /(84 \%)>/ \mathrm{v} /(73 \%)>/ \theta /(30.3 \%)=$ $/ / /(30.3 \%)>/ 3 /(28.2 \%)$. Both two groups received the highest goodness rating in producing $/ \mathrm{S} /$ but the lowest rating in the production of $/ 3 /$.

Three-way ANOVA with fricative, subject group and vowel context as factors was performed on Chinese subjects' goodness rating and the results showed that there were main effects of fricative $[F(7,1392)=721.796, p<.001]$, subject group $[F(1,1392)=$ $1210.309, p<.001]$, and vowel context $[F(2,1392)=8.845, p<.001]$ on the subjects' goodness rating.

A subject group $\times$ fricative interaction $[F(7,1392)=130.588, p<.001]$ was found and corresponding post hoc tests showed that the English majors received significantly higher goodness ratings than the middle school students in producing all the eight fricatives. This meant that longer exposure of L2 improved the pronunciation goodness of all the English fricatives for Chinese EFL learners.

A fricative $\times$ vowel interaction $[F(14,1392)=7.06, p<.001]$ was found and corresponding post hoc tests showed that the differences in Chinese subjects' goodness rating score between the three vowel context were only carried by $/ \mathrm{v} /, / \theta /, / \mathrm{d} /$, and $/ 3 /$. The goodness ratings of $/ \mathrm{v} /$ and $/ \theta /$ were the highest in $/ \mathrm{i} /$ context while those of $/ \mathrm{d} /$ and $/ 3 /$ were the highest in $/ \mathrm{a} / \mathrm{and} / \mathrm{u} /$ contexts respectively.

A non-significant subject group $\times$ vowel interaction $[F(2,1392)=$ .346, $p=.707>.05]$ indicated that the goodness rating differences caused by the variation of vowel contexts were not statistically significant between the English majors and the middle school students.

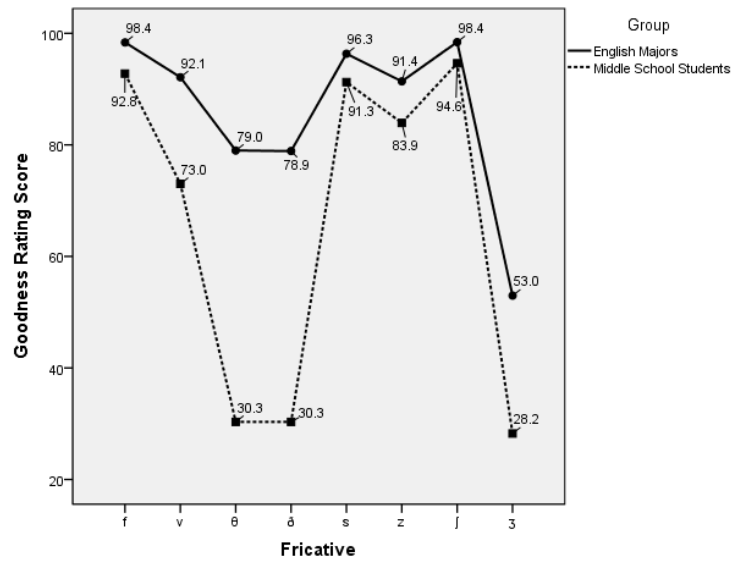

Figure 3. Mean goodness rating score of each English fricative for Chinese subjects

\subsubsection{Summary}

We found different performances between the two subject groups. In most cases, the English majors outperformed the middle school students in perceiving and producing the fricatives. In addition, we also observed that the English majors showed less substitution errors in both perception and production than the middle school students. The current results are in support of previous researches reporting a facilitating effect of longer $\mathrm{L} 2$ exposure on the perception and production of L2 segments (Jia et al., 2006; Wang et al., 2008).

It was also observed that vowel context exerted influence on Chinese subjects' fricative perception and production. This might be related to the observations obtained from the acoustical study on English fricatives by Jongman et al. (2000), which found that the acoustic features of English fricatives varied when the vowel context changed. Despite that there might be mismatch between the acoustic features and the impressionistic judgements, we reckon the variation of acoustic features between different vowel contexts as a possible reason accounting for Chinese subjects' different perceptual and productive performances in different vowel contexts.

\subsection{Perceptual and productive error patterns}

The results in the identification test and intelligibility test were further analyzed in terms of error patterns, as given in the Tables 5-8.

Table 5. Confusion metrics of the eight English fricatives for the English majors

\begin{tabular}{c|c|c|c|c|c|c|c|c}
\hline & \multicolumn{7}{c}{ Target } \\
\cline { 2 - 9 } Res. & $\mathbf{f}$ & $\mathbf{V}$ & $\boldsymbol{\theta}$ & $\boldsymbol{0}$ & $\mathbf{s}$ & $\mathbf{z}$ & $\boldsymbol{J}$ & $\mathbf{3}$ \\
\hline $\mathbf{f}$ & $\mathbf{8 8 . 9}$ & & 34.8 & 6.5 & & & & \\
\hline $\mathbf{V}$ & & $\mathbf{8 7 . 2}$ & & 20.4 & & & & \\
\hline $\boldsymbol{\theta}$ & 5.5 & & $\mathbf{3 9 . 8}$ & 18 & 12.3 & & & \\
\hline $\boldsymbol{0}$ & & 5.5 & 12.1 & $\mathbf{3 1 . 6}$ & 5.4 & 17.3 & & \\
\hline $\mathbf{S}$ & & & 6.8 & & $\mathbf{8 0 . 7}$ & & & \\
\hline $\mathbf{z}$ & & & & 20.3 & & $\mathbf{7 5}$ & & 8.1 \\
\hline $\boldsymbol{J}$ & & & & & & & $\mathbf{9 6}$ & 5.2 \\
\hline $\mathbf{3}$ & & & & & & & & $\mathbf{8 4 . 1}$ \\
\hline
\end{tabular}

Note: Confusion percentage lower than $5 \%$ is not considered for clarity. 
Table 6. Confusion metrics of the eight English fricatives for the middle school students

\begin{tabular}{c|c|c|c|c|c|c|c|c}
\hline \multirow{2}{*}{ Res. } & \multicolumn{7}{|c}{ Target } \\
\cline { 2 - 9 } $\mathbf{f}$ & $\mathbf{8 0 . 3}$ & $\mathbf{v}$ & $\boldsymbol{\theta}$ & $\boldsymbol{\partial}$ & $\mathbf{s}$ & $\mathbf{z}$ & $\boldsymbol{J}$ & $\mathbf{3}$ \\
\hline $\mathbf{v}$ & 6.3 & $\mathbf{6 8 . 7}$ & & 25.1 & & & & \\
\hline $\boldsymbol{\theta}$ & 8.5 & & $\mathbf{2 6 . 3}$ & 20.2 & 10.6 & & & \\
\hline $\boldsymbol{\delta}$ & & 8.9 & 17.5 & $\mathbf{2 0 . 5}$ & 7.3 & 25.4 & & \\
\hline $\mathbf{s}$ & & & 11.6 & & $\mathbf{8 0 . 7}$ & & 6.2 & \\
\hline $\mathbf{z}$ & & & & 23.5 & & $\mathbf{6 4 . 7}$ & & 14.9 \\
\hline $\boldsymbol{J}$ & & & & & & & $\mathbf{9 2 . 3}$ & 7.1 \\
\hline $\mathbf{3}$ & & & & & & 8.5 & & $\mathbf{7 5 . 5}$ \\
\hline
\end{tabular}

Note: Confusion percentage lower than $5 \%$ is not considered for clarity.

Table 7. Substitution patterns for the English majors

\begin{tabular}{c|c}
\hline Fricative (intelligibility) & Substituted sounds \\
\hline $\mathrm{f}(94.7 \%)$ & $\mathrm{w}(28.1 \%)$ \\
\hline $\mathrm{v}(70.7 \%)$ & $\mathrm{f}(5.6 \%), \mathrm{s}(23 \%), \mathrm{z}(7.4 \%), \mathrm{\gamma}(14.2 \%)$ \\
\hline$\theta(51.1 \%)$ & $\mathrm{v}(6.1 \%), \theta(20 \%), \mathrm{z}(22.7 \%)$ \\
\hline$\partial(48.6 \%)$ & $\theta(7.1 \%)$ \\
\hline $\mathrm{s}(90.6 \%)$ & ठ $(13.2 \%)$ \\
\hline $\mathrm{z}(82.2 \%)$ & $\mathrm{d}(15.6 \%), \mathrm{z}(34 \%)$ \\
\hline $\int(95.2 \%)$ &
\end{tabular}

Note: Substitution percentage lower than $5 \%$ is not considered for clarity.

Table 8. Substitution patterns for the middle school students

\begin{tabular}{c|c}
\hline Fricative (intelligibility) & Substituted sounds \\
\hline $\mathrm{f}(89.2 \%)$ & $\theta(6.1 \%)$ \\
\hline $\mathrm{v}(46.6 \%)$ & $\mathrm{w}(43.2 \%)$ \\
\hline$\theta(18.5 \%)$ & $\mathrm{f}(8.2 \%), \mathrm{s}(35.3 \%), \mathrm{z}(8.9 \%), \mathrm{\partial}(21.4 \%)$ \\
\hline$\partial(15.4 \%)$ & $\mathrm{v}(5.2 \%), \theta(27.3 \%), \mathrm{s}(9.6 \%), \mathrm{z}(36.8 \%)$ \\
\hline $\mathrm{s}(87.4 \%)$ & $\theta(8.7 \%)$ \\
\hline $\mathrm{z}(74.1 \%)$ & ठ $(23.3 \%)$ \\
\hline $\int(92.2 \%)$ & $3(5.5 \%)$ \\
\hline $3(24.3 \%)$ & $\mathrm{d}(22.2 \%), \mathrm{z}(45.8 \%)$ \\
\hline
\end{tabular}

Note: Substitution percentage lower than $5 \%$ is not considered for clarity.

In general, Tables 5-8 show that some of the error patterns are shared by the English majors and the middle school students but some others are only observed for the middle school students. Also, in most of the shared error patterns, the error rate is higher for the middle school students than the English majors. Furthermore, some of the error patterns we discovered have been reported by previous studies, while some others are new findings that have not been observed before.

\subsubsection{Error patterns that have been observed by previous researches}

\subsubsection{Substitution of $/ \mathrm{w} /$ for $/ \mathrm{v} /$ in production}

We observed serious $/ \mathrm{v}$-w/ misproductions for both groups, which took up $28.1 \%$ of the whole $/ \mathrm{v} /$ production for the English majors and $46.6 \%$ for the middle school students. Such a pattern is a typical error for Chinese learners of English in producing English $/ \mathrm{v} /$ and has been attested by many previous researches (Cheng \& He, 2008; Hua \& Ran, 2008; Wu, 2008; Zhang \& Xiao, 2014). In line with previous researches, we also attributed this frequently mentioned error pattern to the negative transfer of Chinese. Driven by the principle of "least effort" (Cheng \& He, 2008), Chinese learners could be inclined to replace some strange and difficult L2 sounds that are absent in their L1 with some similar and easy L1 sounds that they are familiar with. Specifically, since $/ \mathrm{v} /$ is a voiced labiodental fricative and $/ \mathrm{w} /$ is a voiced labio-velar approximant, we reckon that it might the labial feature shared by the articulation of these two sounds that made Chinese subjects choose $/ \mathrm{w} /$ as a comfortable substitute for $/ \mathrm{v} /$.

\subsubsection{Confusions of $/ \theta /-/ \mathrm{s} /$ and $/ / /-/ z /$ in both perception and pro- duction}

Another noteworthy error pattern fell on $/ \theta /-/ \mathrm{s} /$ for both the two groups in both perception and production (Tables 5-8), which is a famous error for Chinese learners of English and has been reported by Li (2012), Rau et al. (2009), Sui \& Li (1998), Wu (2008), and Zhang \& Xiao (2014)'s researches. Wu (2008) and Li (2012) attributed such an error pattern to the absence of $/ \theta /$ in Chinese and the articulatory features shared by these sounds. Chinese learners might choose $/ \mathrm{s} /$ to replace $/ \theta /$ since $/ \mathrm{s} /$ has similar counterparts in Chinese. $\mathrm{Wu}$ (2008) also mentioned that Chinese learners' confusion between $/ \theta /, / \delta /$, and /s/, /z/ revealed a deficiency of Chinese English teachers in the teaching of fricative sounds. The teachers fail to provide sufficient explanations on the articulatory characteristics of English $/ \theta /$ and $/ \delta /$ in class, which makes their students easily use $/ \mathrm{s} /$ and $/ \mathrm{z} /$ to replace these two sounds.

Besides, in accordance to the understanding proposed by Sung (2006), who investigated L2 sound perception and production by Korean adult and child learners of English, the confusions of $/ \theta-\mathrm{s} /$ could also be interpreted as the replacement of more marked sounds with less marked ones since the dental fricative $/ \theta$ / is more marked than $/ \mathrm{s} /$. And they proposed that the substitution of $/ \mathrm{s} /$ for $/ \theta /$ is expectable because /s/ has similar counterpart in learners' $\mathrm{L} 1$ and it is less marked than $/ \theta /$, while the opposite substitution pattern was much less possible and should be referred as hypercorrection or overcompensation error (Sung, 2006).

The confusion between $/ \mathrm{d} /$ and $/ \mathrm{z} /$ is also observed in the present study, which is as understandable as the confusion between $/ \theta /$ and $/ \mathrm{s} /$, as $/ \delta /$ and $/ \mathrm{z} /$ are voiced counterparts of $/ \theta /$ and $/ \mathrm{s} /$. Similar to the case of $/ \theta /$ and $/ \mathrm{s} /$, the confusion of $/ \mathrm{\delta} /-\mathrm{z} /$ could also be attributed to following reasons: absence in learners' L1 consonant system, deficiency of L2 teaching, substitution of less marked sounds for more marked ones and hypercorrection.

\subsubsection{Confusion of $/ \mathrm{J} / / / 3 /$ in production}

The middle school students were found misproducing $/ \mathrm{g} /$ as $/ 3 /$ occasionally (5.5\%) in the intelligibility test, which was in line with the results of Zhang \& Xiao (2014)'s empirical research. They claimed that the substitution of $/ \mathrm{J} /$ for $/ 3 /$ was an instantiation of devoicing phenomenon while the substitution of $/ 3 /$ for $/ \mathrm{J} /$ was an unexpected one. However, we provided a different explanation and related such an error pattern to the absence of the voiceless-voiced contrast in Chinese fricative inventory for some Chinese speakers, which could lead to difficulties for them in discriminating English $/ \mathrm{J} /$ and $/ 3 /$. Such an understanding is based on the fact that the presence or absence of voiced fricative in Chinese consonant system is individually decided. For some Chinese, the voiced retroflex fricative / $\mathrm{z} /$ does not exist in their consonant system. Rather, they use the voiced retroflex approximant $/ \mathrm{l} /$ instead. As a consequence of this, they have lost the voiced counterpart of the voiceless retroflex fricative /6/ in their consonant system and could possibly 
become unaware of the voiceless-voiced contrast of $/ \int-3 /$ in English. So it might be the speakers who do not have $/ z$ / in their consonant inventory that misproduced $/ \mathrm{J} / \mathrm{as} / 3 /$ in the intelligibility test.

\subsubsection{Substitution of $/ \mathrm{z} /$ or $/ \mathrm{d} / \mathrm{for} / \mathrm{z} /$ in production}

It was found that both two Chinese subject groups used /z/ to produce $/ 3 /$ considerably ( $34 \%$ and $45.8 \%$ respectively), which might be result from the "equivalence classification" mechanism proposed by Flege (1987) and Bohn \& Flege (1992). Category formation for an L2 sound might be blocked when the L2 sound has similar phone in learner's L1. Acquiring process could get harder than the case where the L2 sound is completely absent from learner's first language. Specifically, under the mechanism of "equivalence classification", Chinese learners might have mistakenly regarded the voiced palato-alveolar fricative $/ 3 /$ in English as the voiced retroflex fricative $/ z$ l in Chinese since the two sounds are both voiced coronal fricatives.

Another serious substitution error observed was the misproduction of $/ 3 /$ as $/ \mathrm{d} / 3 /(15.6 \%$ for the English majors and $22.2 \%$ for the middle school students). This error type has also been reported in Zhang \& Xiao (2014)'s research. Similar to their claim, we also regard such a type as an unexpected one. As suggested by Zhang \& Xiao (2014), substitution of an affricate sound for a fricative sound seems to be in contrast to the simplification tendency in second language acquisition. Affricates are obviously more complex than fricatives by involving two articulatory gestures (stop and fricative). Presumably such a substitution error could be explained by the quantitative inequality of the fricative and affricate sounds in English and Chinese. There are nine fricatives and two affricates in English while the numbers of fricatives and affricates in Chinese are both six. The smaller quantity of fricative sounds and large quantity of affricate sounds in Chinese than in English might increase the possibility for Chinese subjects to substitute an affricate sound for a fricative sound.

\subsubsection{Newly-found error patterns in the present study}

\subsubsection{Confusions of $/ \mathrm{f} /-/ \theta /$ and $/ \mathrm{v} /-/$ / $/$ in both perception and pro- duction}

The misperception and/or misproduction between /f/ and $/ \theta /$ by the Chinese learners were observed in the present study, which has not been well-documented in previous researches. Referring to Lee et al. (2011) and Mi (2014)'s researches which found the same error pattern for Korean learners of English, we ascribed such a pattern to the fact that both $/ \mathrm{f} /$ and $/ \theta /$ are characterized by a relatively flat spectrum and that the overall energies of these two sounds are both rather weak, which consequently could lead to much perceptual confusion even to native speakers of English (Edwards, 2003).

Moreover, both two groups misperceived $/ \mathrm{v} /$ as $/ \mathrm{\delta} /$, which has not been documented in previous research neither and might similarly be explained by the acoustical similarities shared by labio-dental fricatives and dental fricatives (Jongman et al. 2000), as in /f/ and / $/$ /.

\subsubsection{Confusion of $/ \theta /-ð /$ in both perception and production}

The confusion of $/ \theta /-/ \delta /$ occurred both perceptually and productively for the two groups of Chinese learners. Such a serious pattern has not been reported by previous studies, of which the possible reason might be that these two dental fricatives differ only in voicing and share all the other place and manner features. The absence of these two sounds in Chinese consonant inventory hinders Chinese learners from establishing contrastive categories for these two sounds, therefore resulting in perceptual and productive confusions. Zhang \& Xiao $(2011,2014)$ have investigated this pair in their researches but found Chinese learners did not show much difficulty in distinguishing these two sounds perceptually and productively and obtained much higher accuracy rate than the present study. What caused the behavioral differences between Zhang \& Xiao (2011, 2014)'s researches and the present study might be the difference in experimental method. Zhang \& Xiao (2011, 2014) used a discrimination task where the subjects were asked to listen to the recordings and tell the difference between the two fricatives in each word pair while the present study conducted an eight-choice identification test in which the subjects needed to choose the single target fricative from eight options provided. The subjects in Zhang \& Xiao (2011, 2014)'s studies might subconsciously be aware of the differences between the two fricatives in each word pair to some extent and therefore showed relatively good performances.

\subsubsection{Confusion of $/ z /-/ 3 /$ in perception}

The confusion between $/ z /$ and $/ z /$ was found in our research, which only occurred in the perception of the middle school students (/z/ to /z/: $8.5 \% ; / 3 /$ to /z/: $14.9 \%$ ) and has never been reported by any of the previous researches. This was not a serious fricative confusion in that it might be an example of "Two-Category Assimilation" type (TC type), as defined by PAM (hereafter) (Best, 1995). / $\mathbf{z}$ / is most likely assimilated to the affricate /ts/ in Chinese by the Chinese learners because of their auditory and articulatory similarities (Cheng \& He, 2008; Niu, 2017), whereas /3/ might be equalized as $/ z /$ in Chinese with the greatest possibility in that both $/ 3 /$ and $/ z /$ are voiced coronal fricatives, which share all the other distinctive features except for [ \pm anterior]. Besides, the results of the intelligibility test provided evidence for our deduction, in that the Chinese learners confused $/ 3 /$ and $/ z /$ to a large extent $(34 \%$ for the English majors and $45.8 \%$ for the middle school students). Therefore, based on the understanding proposed by PAM, the L2 sound contrast / $/$ / and $/ 3 /$ is respectively similar to two of learners' L1 sound categories. In such a case, the difficulty of sound distinguishing is not in a high level.

\subsubsection{Confusion of $/ \mathbf{f} /-/ \mathbf{v} /$}

The middle school students were found misperceiving $/ \mathrm{f} /$ as $/ \mathrm{v} /$ $6.3 \%$ of the time and misperceiving $/ \mathrm{v} /$ as $/ \mathrm{f} / 13.7 \%$ of time. This accorded with Xiao (2013) and Zhang \& Xiao (2014)'s researches because this error pattern only occurred perceptually. Chinese learners were confused by these two sounds in identification, but they did not use /f/ to replace $/ \mathrm{v} /$ when producing them or vice versa. But the results of the present study differed from those of Xiao (2013) and Zhang \& Xiao (2014)'s studies in that the subjects in their studies confused /f/ with /v/ with much lower degree than the present study and the authors reported there was no serious confusion between / $\mathrm{f} /$ and $/ \mathrm{v} /$ for Chinese EFL learners. Such a discrepancy between research results might also be attributed to the different experimental methods. Xiao (2013) and Zhang \& Xiao (2014) used discrimination tasks and the subjects might subconsciously be aware of the differences between the two fricatives in the word pairs. 


\subsection{Correlation between perception and production of English} fricatives

The experiments in the present study yielded mixed results regarding the perception-production relationship, some of which accorded with previous researches while some of which were in contrast with them. First, it was found that the fricative perception and production of the English majors were weakly correlated while those of the middle school students were medially correlated (Table 9). The moderate perception-production correlation of the middle school students was in concordance with the researches that observed a moderate correlation between perception and production (BettoniTechio, 2007; Flege et al., 1997, 1999; Kluge, 2007). Moreover, we observed that the overall identification accuracies were higher than the overall intelligibility scores for the middle school students (Table 10), which indicated a precedence of perception over production and therefore accorded with previous researches which proposed that perception is a necessary prerequisite for production (Joh \& Lee, 2001; Rochet, 1995). However, group differences could not be neglected. The perception-production correlation and difference of the English majors were much lower in degree than those of the middle school students (Table 9 and Table 10). Given that the English majors in the present study were all English majors, who have taken English phonetics courses and received systematic pronunciation training for at least three years, in accordance with Sheldon \& Strange (1982), who claimed that "drills in production do not necessarily benefit perceptual learning", we therefore attributed such a finding to the fact that a specialized training on pronunciation may lead to a unilateral growth of learners' pronunciation ability, which might reduce the perception-production difference and weaken the correlation between them. Moreover, L2 perception and production may also be affected by many other factors. As proposed by Llisterri (1995), it is seemingly impossible to infer production abilities from perceptual ones or vice versa in that L2 perception and production are complicated issues, which might be dependent on many factors like the age of acquisition, length of the exposure to L2, the influence of L1 sound system, quality of L2 input, and social pressure, along with acoustic cues and contextual dependency. The frequent interactions between these factors greatly increase the complexity of this perception-production relationship issue.

Furthermore, an uncorrelated perception and production was attested in the correlation analyses on each fricative individually. The significantly correlated perception and production were only manifested in /f/ $(r=.22, p=.037<.05)$ and $/ ð /(r=.258, p=.014<.05)$ for the English majors and in $/ \mathrm{d} /(r=.37, p=.000)$ and $/ 3 /(r=.221$, $p=.036$ ) for the middle school students. Besides, comparative analyses on each fricative also demonstrated that the better identification than intelligibility was only attested in $/ \mathrm{v} /(p<.001)$ and $/ 3 /(p<.001)$ for the English majors and in $/ \mathrm{v} /(p<.001), / \Theta /(p<.001), / \mathrm{d} /(p<.001)$ and $/ 3 /(p<.001)$ for the middle school students. The incomplete perception-production correlations and differences imply that those who could well identify the English fricatives might not always be capable of producing highly intelligible fricatives, and those whose fricative production was highly intelligible to native speakers were not always able to respond accurately in identifying them. The realization of a good pronunciation might not always need a good identification as a prerequisite.
Table 9. Correlation for mean overall scores between identification and intelligibility and between identification and goodness rating

\begin{tabular}{c|c|c}
\hline $\begin{array}{c}\text { Pairs of } \\
\text { comparison }\end{array}$ & $\begin{array}{c}\text { Correlation } \\
\text { (English majors) }\end{array}$ & $\begin{array}{c}\text { Correlation } \\
\text { (middle school students) }\end{array}$ \\
\hline $\begin{array}{c}\text { Identification } \\
\text { vs } \\
\text { Intelligibility }\end{array}$ & $r=.451, p<.001^{* * *}$ & $r=.67, p<.001^{* * *}$ \\
\hline $\begin{array}{c}\text { Identification } \\
\text { vs } \\
\text { Goodness }\end{array}$ & $r=.187, p<.001^{* * *}$ & $r=.627, p<.001^{* * *}$ \\
\hline
\end{tabular}

Table 10. T-tests for mean overall scores between identification and intelligibility

\begin{tabular}{|c|c|c|c|}
\hline Group & Tests & $\begin{array}{c}\text { Results } \\
\text { (overall) }\end{array}$ & $\begin{array}{c}\text { Significance of } \\
\text { difference }\end{array}$ \\
\hline \multirow{2}{*}{ English major } & Identification & 72.9 & \multirow{2}{*}{$p=.278>.05$} \\
\hline & Intelligibility & 71.8 & \\
\hline \multirow{2}{*}{$\begin{array}{l}\text { Middle school } \\
\text { student }\end{array}$} & Identification & 62.6 & \multirow{2}{*}{$p<.001$} \\
\hline & Intelligibility & 56 & \\
\hline
\end{tabular}

Additionally, what should be mentioned was that comparative statistical analyses on Chinese learners' identification accuracy and goodness rating were not conducted in that the goodness judgement made by the native speaker judges could be subjective and largely be dependent on the standards of their own. The goodness rating might be much lower if two raters with harsh rating standards were recruited in the experiment or vice versa. This reflects the problem regarding the research question of "perception-production relationship" mentioned by Peperkamp \& Bouchon (2011). They proposed that comparing performances in perception experiments with those in production experiments might be difficult sometimes because of differences in the experimental methods adopted for the two modalities. An alternative way to examine the perception-production relationship is to focus on investigating the statistical correlations between them. Therefore in the present study we will only suggest the understanding that the goodness rating and identification was overall medially correlated but the correlation was not manifested in all the eight fricatives.

\section{Conclusions}

By adopting an identification test, an intelligibility test and a goodness rating test, this study investigated sixty Chinese EFL learners' perception and production of eight English fricatives. The results of the study, on the whole, provide some important findings and suggestions for English learning and teaching.

Firstly, the study demonstrated both strengths and weaknesses of Chinese EFL learners' perception and production of English fricatives, from which L2 learners and teachers might benefit to be clear about the directions in English learning and teaching. On the whole, learners were confronted with more difficulties than facilities in English fricative acquisition, as they showed less errors only for $/ \mathrm{f} /$, $/ \mathrm{s} /$, and $/ \mathrm{J} /$. As weakness has been observed to exist in $/ \mathrm{v} /, / \theta /, / \mathrm{d} /$, $/ z /$, and $/ z /$, top priority should be given to these sounds and the focus should be placed on the avoidance of the substitution errors. In addition, the inconsistency of results with previous studies reveals the complexity of Chinese EFL learners' fricative acquisition and the need for more empirical researches. Claims based on personal teaching experiences are not suggested and future studies should be 
encouraged to be conducted empirically.

Secondly, as the negative transfer of Chinese has been proven to interfere with Chinese learners' English learning, it is suggested that teachers focus on helping their students to avoid negative transfer in order to enhance teaching efficiency. For instance, teachers could emphasize the contrasts between English and Chinese fricatives in class, rather than teaching English fricatives alone, so as to make their students truly understand the auditory and articulatory differences between English and Chinese fricatives.

Thirdly, it was found that perception was not always correlated with production or vice versa. L2 perception and production might be dependent on many factors and inferring production abilities from perceptual ones or vice versa was a hard task. Therefore it is suggested that learners should participate in specialized perceptual or productive training to enhance their L2 perception or production because the two modalities might develop unilaterally and focusing on one aspect might not bring benefit to the other.

Lastly, the present study is not free of limitations in that the role of L2 proficiency on L2 fricative perception and production was not investigated. It is not suggested to use different proficiency tests to assume that the subjects were differed by their English proficiency levels because defining English proficiency level based on the results of different types of tests may reduce the reliability of the research results. Since one subject group in the present study consisted of college students while the other was composed of middle school students, it was difficult to say that the two groups differed only in L2 proficiency. Therefore, it was hard to infer whether L2 proficiency played a role in influencing Chinese learners' fricative perception and production in the present study. Future researches should use more rigorous ways to control subjects' L2 proficiency levels so as to more reliably investigate the role of L2 proficiency level in L2 perception and production.

\section{References}

Aoyama, K., Flege, J. E., Guion, S. G., Akahane-Yamada, R., \& Yamada, T. (2004). Perceived phonetic dissimilarity and L2 speech learning: The case of Japanese /r/ and English /1/ and /r/. Journal of Phonetics, 32(2), 233-250.

Best, C. T. (1995). A direct realist view of cross-language speech perception. In Strange W. (Ed.), Speech perception and linguistic experience: Issues in cross-language research (pp. 171-206). Baltimore, MD: York Press.

Bettoni-Techio, M., Rauber, A. S., \& Koerich, R. D. (2007, August). Perception and production of word-final alveolar stops by Brazilian Portuguese learners of English. Proceeding of Interspeech 8 (pp. 2293-2296). Antwerp, Belgium.

Bohn, O. S., \& Flege, J. E. (1990). Interlingual identification and the role of foreign language experience in L2 vowel perception. Applied Psycholinguistics, 11(3), 303-328.

Bohn, O. S., \& Flege, J. E. (1992). The production of new and similar vowels by adult German learners of English. Studies in Second Language Acquisition, 14(2), 131-158.

Chen, X. (2012). A linear regression analysis on TEM4. Journal of Civil Aviation Flight University of China, 6, 020.

Chen, X. X. (2011). Nanfang hanyu youer yiyaxueyu yu zaoqi yuyanfazhan genzongxing gean yanjiu [Babbling vocalizations and early speech of southern Mandarin: A longitudinal case study] (Doctoral dissertation). Hunan University, Hunan, China.
Chen, H., \& Bi, R. (2008). Yingyu zhuanye xuesheng langdu renwu zhong yuyin nengli de fazhan yanjiu moshi [English majors' pronunciation and intonation in read speech: A longitudinal study]. Jiefangjun Waiguoyu Xueyuan Xuebao, 31(4), 43-49.

Cheng, C. M. (2006). Yingyu xuexizhe kouyu zhong de yinduan cuowu fenxi [Analysis of segmental errors in English learners' oral English]. Guangxi Jiaoyu Xueyuan Xuebao, 1, 111-112.

Cheng, C. M., \& He, A. P. (2008). Gaoji yingyu xuexizhe kouyu yinduan cuowu fenxi - Yixiang jiyu yuliaoku de yanjiu [An analysis of oral segmental errors of advanced English learners - A corpus-based study]. Jiefangiun Waiguoyu Xueyuan Xuebao, 31(1), $38-42$.

Duanmu, S. (2007). The phonology of standard Chinese (2nd ed.). Oxford, UK: Oxford University Press.

Edwards, H. (2003). Applied phonetics: The sounds of American English. New York: Thomson.

Flege, J. E. (1987). The instrumental study of L2 speech production: Some methodological considerations. Language Learning, 37(2), 285-296.

Flege, J. E. (1995). Second language speech learning: Theory, findings, and problems. In Strange W. (Ed.), Speech perception and linguistic experience: Issues in cross-language research (pp. 233-277). Baltimore, MD: York Press.

Flege, J. E., Bohn, O. S., \& Jang, S. (1997). Effects of experience on non-native speakers' production and perception of English vowels. Journal of Phonetics, 25(4), 437-470.

Flege, J. E. (1999, August). The relation between L2 production and perception. In J. Ohala, Y. Hasegawa, M. Ohala, D. Granveille \& A. Bailey (Eds.), Proceedings of the XIVth International Congress of Phonetics Sciences (pp. 1273-1276). San Francisco, CA.

Flege, J. E., MacKay, I. R., \& Meador, D. (1999). Native Italian speakers' perception and production of English vowels. The Journal of the Acoustical Society of America, 106(5), 2973-2987.

Jia, G., Strange, W., Wu, Y., Collado, J., \& Guan, Q. (2006). Perception and production of English vowels by Mandarin speakers: Age-related differences vary with amount of L2 exposure. The Journal of the Acoustical Society of America, $119(2), 1118-1130$.

Jin, Y., \& Fan, J. (2011). Test for English majors (TEM) in China. Language Testing, 28(4), 589-596.

Jongman, A., Wayland, R., \& Wong, S. (2000). Acoustic characteristics of English fricatives. The Journal of the Acoustical Society of America, 108(3), 1252-1263.

Kluge, D. C., Rauber, Aan learners of English. Proceeding of Interspeech 8 (pp. 2297-2300). Antwerp, Belgium.

Ladefoged, P., \& Johnson, K. (2014). A course in phonetics. Toronto, ON: Nelson Education.

Ladefoged, P., \& Maddieson, I. (1996). The sounds of the world's languages (Vol. 1012). Oxford, UK: Blackwell.

Lado, R. (1957). Linguistics across cultures. Applied linguistics for language teachers. Ann Arbor, MI: University of Michigan Press.

Lee, W. S., \& Zee, E. (2003). Standard Chinese (Beijing). Journal of the International Phonetic Association, 33(1), 109-112.

Lee, S., Joh, J., Lim, I., \& Ko, H. (2011). The production of English sounds by early learners with different English learning experience. Korean Journal of Linguistics, 36(1), 215-241.

Li, T. (2012). The research on the acquisition of English fricatives by Chinese EFL learners in middle school (MA thesis). Liaoning Normal University, Liaoning, China. 
Lin, Y. H. (2007). The sounds of Chinese (vol. 1). New York, NY: Cambridge University Press.

Lin, T., \& Wang, L. J. (1992). Yuyinxue jiaocheng [Phonetics: A course book]. Beijing, China: Beijingdaxue Chubanshe.

Llisterri, J. (1995, August). Relationships between speech production and speech perception in a second language. Proceedings of the 13th International Congress of Phonetic Sciences (Vol. 4, pp. 92-99). Stockholm, Sweden.

Major, R. C. (2001). Foreign accent: The ontogeny and phylogeny of second language phonology (1st ed.). Abingdon, UK: Routledge.

Mi, J. (2014). Perception of English consonants in different prosodic positions by Korean learners of English. Phonetics and Speech Sciences, 6(1), 11-19.

Moeller, \& Pat, M. (2007). Current state of knowledge: psychosocial development in children with hearing impairment. Ear and Hearing, 28(6), 729-739.

Niu, L. L. (2017). Yingyu zhuanye xuesheng yingyu mocayin fayin xianzhuang diaocha yanjiu [A survey on English fricative pronunciation of English majors]. Kaoshi zhoukan, 47, 103.

Owolabi, D. (2012). Production and perception problems of English dental fricatives by Yoruba speakers of English as a second language. Theory and Practice in Language Studies, 2(6), 1108-1113.

Peperkamp, S., \& Bouchon, C. (2011, August). The relation between perception and production in L2 phonological processing. Proceedings of the 12th Annual Conference of the International Speech Communication Association (Interspeech 2011) (pp. 161-164). Florence, Italy.

Pike, K. L. (1943). Phonetics: A critical analysis of phonetic theory and a technique for the practical description of sounds. Ann Arbor, MI: University of Michigan Press.

Rau, D. V., Chang, H. H. A., \& Tarone, E. E. (2009). Think or sink: Chinese learners' acquisition of the English voiceless interdental fricative. Language Learning, 59(3), 581-621.

Rochet, B. L. (1995). Perception and production of second-language speech sounds by adults. In Strange W. (Ed.), Speech perception and linguistic experience: Issues in cross-language research (pp. 379-410). Baltimore, MD: York Press.

Sheldon, A., \& Strange, W. (1982). The acquisition of /r/ and /1/ by Japanese learners of English: Evidence that speech production can precede speech perception. Applied Psycholinguistics, 3(3), 243261.

Sui, Z. H., \& Li C. B. (1998). Yingyu yuyin jiaoxue zhong de wuqu fenxi [Analysis of errors in teaching English pronunciation]. Zaozhuang Xueyuan Xuebao 2, 78-80.

Sung, E. Y. (2006). L2 sound perception and production by Korean adults and children. Studies in Phonetics, Phonology and Morphology, 12(3), 577-596.

Tian, X. H. (2015). Yingyu zhuanye siji kaoshi de xindu yu xiaodu yanjiu [A Study on the Reliability and Validity of TEM 4]. Linqu Jiaoxue 1, 42-43.

Tsukada, K., Birdsong, D., Bialystok, E., Mack, M., Sung, H., \& Flege, J. (2005). A developmental study of English vowel production and perception by native Korean adults and children. Journal of Phonetics, 33(3), 263-290.

Wang, Y., Behne, D. M., \& Jiang, H. (2008). Linguistic experience and audio-visual perception of non-native fricatives. The Journal of the Acoustical Society of America, 124(3), 1716-1726.

$\mathrm{Wu}$, J. X. (2008). Hanying cayin duibi fenxi [Comparison between
Chinese and English Fricatives]. Mudanjiang Shifan Xueyuan xuebao, 5, 69-70.

Xiao, J. (2013). Yingyu mocayin fayin changjian wenti yu duice [Common problems in the pronunciation of English fricatives and the countermeasures]. Kejiao Wenhui, (10), 128-129.

Zhang, Y., \& Lee, S. (2018). Acoustic characteristics and the perception of English voiceless fricatives: A preliminary study on Chinese EFL learners. The Journal of Mirae English Language and Literature, 23(3), 347-367.

Zhang, Y., \& Xiao, J. (2011). A study of Chinese EFL learners' acquisition of English fricatives. 16th Conference of the Pan-Pacific Association of Applied Linguistics (pp. 142-148). Hong Kong, China.

Zhang, Y., \& Xiao, J. (2012). Yinghan mocayin bijiao yu yingyu mocayin xide yanjiu [A study on the comparison between English and Chinese fricatives and the acquisition of English fricatives]. The Tenth National Symposium of the China Association for Comparative Studies of English and Chinese and the 2012 International Symposium on Comparative Studies of English and Chinese and Translation Studies (pp.185-197). Wuhan, China.

Zhang, Y., \& Xiao, J. (2014). An analysis of Chinese students' perception and production of paired English fricatives: From an ELF perspective. Journal of Pan-Pacific Association of Applied Linguistics, 18(1), 171-192.

\section{- Buyi Zhang}

Graduate Student, Department of English Language and Literature Wonkwang University 460 Iksan-daero, Sin-dong

Iksan, 54538 Korea

Tel: +82-63-850-6913

Email: zby747059340@gmail.com

Fields of interest: Phonetics

- Jiaqi Zhang, Corresponding author

Graduate Student, Department of English Language and Literature Wonkwang University 460 Iksan-daero, Sin-dong

Iksan, 54538 Korea

Tel: +82-63-850-6913

Email: zjq496166366@gmail.com

Fields of interest: Phonetics

\section{- Sook-hyang Lee}

Professor, Department of English Language and Literature

Wonkwang University

460 Iksan-daero, Sin-dong

Iksan, 54538 Korea

Tel: +82-63-850-6913

Email: shlee@wku.ac.kr

Fields of interest: Phonetics 